\title{
UM ESTUDO EMPÍRICO SOBRE A CONSENSUALIDADE NA ATIVIDADE EXTRAJUDICIAL DO MINISTÉRIO PÚBLICO FEDERAL EM MATÉRIA DE IMPROBIDADE ADMINISTRATIVA
}

\author{
Daniela Thomes Coelho* \\ João Felipe Viegas Figueira de Mello**
}

\begin{abstract}
RESUMO: A Lei $\mathrm{n}^{\circ}$ 8.429/92 (Lei de Improbidade Administrativa) foi alterada pela Lei $\mathrm{n}^{\circ}$ 13.964/2019, tendo sido introduzido o acordo de não persecução cível (ANPC) em matéria de improbidade administrativa. Esta pesquisa buscou identificar se essa alteração legislativa representa verdadeira inovação no ordenamento jurídico. Em exame empírico, realizou-se um levantamento sobre o quantitativo de acordos homologados no âmbito do Ministério Público Federal, ao longo do tempo, examinando-se os dados antes e depois da Lei $n^{\circ} 13.964 / 2019$. Os achados apontam que a realidade estudada não foi significativamente impactada. Conclui-se que a modificação legislativa representa mera ratificação de prática já usual.
\end{abstract}

PALAVRAS-CHAVE: Direito administrativo sancionador; Controle da administração pública; Improbidade administrativa; Consensualidade; Ministério público federal.

\section{AN EMPIRICAL STUDY ON THE CONSENSUALITY IN THE EXTRAJUDICIAL ACTIVITY OF THE FEDERAL PUBLIC PROSECUTOR'S OFFICE IN MATTERS OF ADMINISTRATIVE IMPROBITY}

\begin{abstract}
The civil non-prosecution agreement is a procedural tool in matters of administrative improbity, introduced by the Act n. 13,964/2019. This research sought to identify whether this legislative change represents true innovation in the legal system. In an empirical examination, a survey was carried out on the number of agreements approved by the Federal Prosecutor's Office, over time, examining the data before and after the Act n. 13,964/2019. The findings indicate that the studied reality was not significantly impacted. It is concluded that the legislative modification represents a mere ratification of an already usual practice.
\end{abstract}

KEY-WORDS: Administrative sanctioning law; Control of public administration; Administrative improbity; Consensuality; Federal prosecutor's office.

\footnotetext{
* Mestranda em Direito da Regulação pela Escola de Direito do Rio de Janeiro da Fundação Getúlio Vargas (FGV DIREITO RIO), graduada em Direito pela Universidade Federal do Espírito Santo (UFES).

Praia de Botafogo, 190, Botafogo, Rio de Janeiro - RJ, 22250-900

danithomes@gmail.com

** Mestrando em Direito da Regulação pela Escola de Direito do Rio de Janeiro da Fundação Getúlio Vargas (FGV DIREITO RIO), graduado em Direito pela Universidade Cândido Mendes (UCAM).

Rua General Garzon, 22, sala 503, Lagoa, Rio de Janeiro - RJ, 22470-010

joaofelipemello@gmail.com
}

Revista de Política Judiciária, Gestão e Administração da Justiça | e-ISSN: 2525-9822 |

Encontro Virtual | v. 7 | n. 1 | p. 38 - 59 | Jan/Jul. 2021. 


\section{INTRODUÇÃO}

A Lei $n^{\circ}$ 8.429/92 (Lei de Improbidade Administrativa) foi recentemente alterada pela Lei no 13.964/2019. Trata-se da introdução do acordo de não persecução cível (ANPC) em matéria de improbidade administrativa. Esta pesquisa ${ }^{1}$ busca identificar se essa alteração legislativa representa verdadeira inovação jurídica ${ }^{2}$.

De um lado, tem-se a hipótese de que a consensualidade não fosse admitida em matéria de improbidade administrativa, na medida em que existia expressa vedação na Lei n 8.429/92. Sob essa ótica, a alteração legislativa implementada pela Lei $\mathrm{n}^{\circ}$ 13.964/2019 teria introduzido uma inovação jurídica. Nesse caso, o resultado esperado seria um aumento no quantitativo de acordos sobre a matéria. Isso porque há ampla literatura que destaca os benefícios de uma solução negociada, que surge como uma tendência, mesmo no ambiente público, conforme explorado no item 1.

Por outro lado, coloca-se como hipótese alternativa que a modificação legislativa pudesse representar mera ratificação de prática já usual. Ou seja, a vedação então expressa na Lei $\mathrm{n}^{\mathrm{o}} 8.429 / 92$ poderia já ter sido contornada, no sentido de serem admitidos acordos em matéria de improbidade administrativa, com fundamento em outras leis e atos infralegais. Logo, oportuno um estudo da evolução normativa de acordos em matéria de improbidade administrativa, desenvolvido no item 2. Nessa perspectiva, a alteração legislativa representaria uma consolidação da realidade. Como resultado, seria esperado que a Lei nº 13.964/2019 não provocasse uma variação no quantitativo de acordos.

A elucidação da questão, portanto, depende de um exame empírico, conforme exposto no item 3. Foi selecionado como objeto de estudo o âmbito extrajudicial do Ministério Público

\footnotetext{
${ }^{1}$ Este artigo é resultado de estudo desenvolvido no âmbito do Grupo de Pesquisa sobre Controle da Administração Pública da FGV Direito Rio. Os autores agradecem ao supervisor do grupo, Prof. Dr. Eduardo Jordão, e aos demais participantes, pelas valiosas contribuições.

${ }^{2}$ Registre-se que a Lei $n^{\circ}$ 13.964/2019 entrou em vigor em 23/01/2020. Trata-se de modificação recente e, portanto, o cenário observado até o momento em que este estudo foi desenvolvido pode ser entendido como espaço de tempo curto e insuficiente para conclusões definitivas. Apesar dessa ressalva, entende-se que o exame dos dados referentes à ocasião da transição são indicadores de possível tendência, a carecer de confirmação quando a vigência da lei contar com um maior período de duração.
} 
Federal $^{3}$. Empregou-se, como metodologia, a análise de dados disponibilizados pela $5^{\text {a }}$ Câmara de Coordenação e Revisão (5 $\left.5^{\mathrm{a}} \mathrm{CCR} / \mathrm{MPF}\right)$, órgão especializado em matéria de corrupção. Incluise, em sua atribuição, a homologação de acordos e de arquivamentos, referentes à atividade extrajudicial ministerial. Assim, o monitoramento dessa atividade tem o potencial de desvendar a questão de pesquisa ora investigada. Buscou-se, com a análise dos dados, a identificação de uma alteração, ao longo do tempo, do quantitativo de acordos homologados sobre essa matéria. Registre-se que a metodologia revela resultado parcial, já que não incluiu o exame de acordos judiciais. Os achados apontam que a realidade estudada não foi significativamente impactada com a edição da Lei $\mathrm{n}^{\circ}$ 13.964/2019. Portanto, comprovou-se a hipótese de que a consensualidade, em matéria de improbidade administrativa, já era uma realidade mesmo antes da introdução do ANPC.

Cumpre destacar, ainda, como resultado da apuração, a conclusão de que os acordos em matéria de improbidade administrativa são firmados por meio de diferentes instrumentos, e não apenas ANPC. Essa situação representa uma dificuldade para o controle social. Isso porque inexiste um banco de dados organizado que inclua informações de todos os agentes ímprobos beneficiados com algum tipo de acordo. Por outro lado, essa opacidade também prejudica o controle social sobre a liberalidade da negociação exercida por cada membro do Ministério Público. Significa que o conteúdo dos acordos não é de fácil acesso ao público, circunstância que deixa o controlador sem qualquer tipo de controle.

\section{A CONSENSUALIDADE EM PROCESSOS ADMINISTRATIVOS SANCIONADORES: INTERESSE PÚBLICO E BENEFÍCIOS SISTÊMICOS}

O sistema punitivo estatal segrega-se em dois regimes distintos: o Direito Administrativo Sancionador e o Direito Penal. Enquanto o Direito Administrativo Sancionador é tradicionalmente voltado à defesa dos interesses da própria Administração Pública, aplicando-se às pessoas a ela submetidas pela via estatutária, o Direito Penal visa à defesa de um interesse global, ou seja, da sociedade como um todo, aplicando-se indistintamente a todos. Tal distinção é facilmente observável a partir da análise da origem desses ramos do Direito, sendo o Direito

\footnotetext{
${ }^{3}$ Optou-se por excluir da análise a atuação dos Ministérios Públicos Estaduais na medida em que a normatização não é uniforme, situação que dificulta a análise. Ademais, há obstáculo na disponibilização de dados referentes à atuação desses órgãos estaduais.
}

Revista de Política Judiciária, Gestão e Administração da Justiça | e-ISSN: 2525-9822 | 
Administrativo Sancionador ligado ao poder de polícia estatal e à guarda do interesse público e o Direito Penal originado da preocupação iluminista de defesa dos interesses individuais como limitação do poder punitivo do Estado (MACHADO, 2020).

Mais recentemente, conforme o Estado foi se retirando da posição de agente econômico para se tornar regulador da ordem econômica e social, a atuação do Poder Público passou a ser também a de conformar o comportamento dos agentes econômicos privados aos desígnios legais, por meio da fiscalização e da punição (VORONOFF, 2019), fazendo surgir um novo Direito Administrativo Sancionador, que não mais se caracteriza por uma relação de mera subordinação, mas sobretudo de cumprimento da ordem jurídica.

Devido a essa evolução histórica, o Direito Administrativo Sancionador e o Direito Penal hoje possuem um arcabouço principiológico convergente, havendo, em ambos, necessidade de observância de salvaguardas aos indivíduos, entre as quais, o devido processo legal e a proporcionalidade da pena. Isso limita o poder punitivo estatal, tendo reduzido sua margem de discricionariedade, e impondo-lhe o cumprimento de exigências processuais que modificaram o Processo Administrativo Sancionador.

A edição de leis gerais de processo administrativo se deu exatamente para atender a esse propósito garantista e para uniformizar a atuação da atividade administrativa, que se caracteriza pela confluência de diversos atos praticados ao longo do tempo e que não se esgotam em si. Tal garantismo resultou na observância de ritos potencialmente onerosos para a Administração Pública. Onerosos porque a autoridade sancionadora, para que possa exercer seu poder punitivo, precisa estar a todo tempo atenta ao cumprimento de um procedimento que confira ao acusado o exercício de sua ampla defesa e de seus direitos fundamentais. Dentre os direitos fundamentais está incluída a presunção de inocência, que exige razoável conjunto probatório para se condenar e aplicar uma punição ao acusado (OSÓRIO, 2020) ${ }^{4}$. Não se está aqui a fazer qualquer crítica desse tipo de exigência, mas tão somente constatando que isso torna o Processo Administrativo Sancionador, via de regra, longo e oneroso.

\footnotetext{
${ }^{4}$ No âmbito do MPF, o regramento da atuação extrajudicial é regulamentado pela Resolução CSMPF no 8/2006. O referido normativo prevê prazos e forma de tramitação do inquérito civil público e, dentre seus aspectos fundamentais, destacam-se: seu caráter público; necessidade de documentação de todas as diligências realizadas; possibilidade recursal; necessidade de fundamentação; supervisão das decisões pela respectiva Câmara de Coordenação e Revisão.
} 
Se, por um lado, o rito procedimental atende ao garantismo, por outro, ele enseja a perda de eficiência administrativa, que, nas palavras de Odete Medauar "liga-se à ideia de ação que leve à ocorrência de resultados de modo rápido e preciso" de modo a permitir ao Estado a “obte[nção] [d]o máximo de resultado" (MEDAUAR, 2017, p. 315). A eficiência pode ser, assim, equiparada à boa administração, à otimização das decisões administrativas discricionárias ou simplesmente como escolha do meio mais adequado para determinar decisões eficientes (DE PALMA, 2015). Em qualquer dessas três modalidades conceituais, confere-se ao agente público um campo de atuação repleto de possibilidades, que precisam ser escolhidas de forma desinteressada ou, simplesmente, isenta de conflito de interesses.

Verifica-se, a partir daí, que, para alcançar a eficiência, a Administração Pública se veja instigada a buscar atalhos capazes de otimizar a sua função administrativa sancionadora. Diante dessa realidade e, levando-se em consideração que a atividade fiscalizatória e sancionatória possui, quase sempre, uma desvantagem informacional com relação ao potencial infrator, a Administração Pública acaba enxergando a consensualidade como instrumento que oferece um atalho para redução do custo e da duração do processo, que, ao mesmo tempo, é capaz de reduzir as observadas assimetrias informacionais (GARCIA, 2017).

Nesse esteio, o uso da consensualidade confere ao Direito Administrativo Sancionador um caráter funcional (DE PALMA, 2015; BOBBIO, 2007), que escapa à concepção binária clássica do proibido versus o permitido e viabiliza a construção de uma solução negociada mais eficaz do que o mero sim ou não. A consensualidade, enquanto atuação não imperativa, pressupõe a negociação, traduzida na dinâmica existente entre proposições, aceitações e recusas, que não necessariamente chega a termo por meio da convergência de vontades.

A flexibilização da atuação da administração pública para a via consensual permite que se implemente o dinamismo negocial entre atores públicos e privados no campo do Direito Administrativo, passando tais atores a se relacionarem não apenas em contraposição entre si como se dá no quadro da atuação imperativa -, mas em colaboração ${ }^{5}$.

\footnotetext{
${ }^{5}$ Essa escola é conhecida como Renew Deal School (LOBEL, 2004; FREEMAN, 2000).
} 
A eficiência desse instrumental para o controle de abusos e ilegalidades é validada por diversos estudos dedicados à análise utilitarista de métodos de enforcement ${ }^{6}$, os quais defendem que a Administração Pública não deve se valer da utopia de punir a totalidade dos infratores ${ }^{7}$. Uma tal postura revelar-se-ia ineficiente e contrária a um nível ótimo do controle. Em estudo seminal sobre o tema, Gary Becker (1968) pontuou que o nível ótimo de controle (enforcement) se dá num ponto em que os custos extras da atividade de controle excedem os benefícios que decorreriam de seu controle pleno e efetivo. O mesmo se pode dizer a respeito do controle dos atos dos agentes públicos, fazendo valer a ideia de que o abuso do poder governamental não é algo a ser estritamente minimizado, mas tão somente otimizado (VERMEULE, 2019).

Nessa linha, o Direito Administrativo Sancionador tem se utilizado cada vez mais de instrumentos de consensualidade como meios alternativos à clássica sanção, chamados, por alguns, simplesmente de acordos substitutivos, pelo "efeito terminativo do processo administrativo no qual são celebrados", substituindo a "decisão unilateral e imperativa da Administração Pública" (DE PALMA, 2015, p. 252). Enquadram-se nessa categoria os Termos de Ajustamento de Conduta (TAC), os Termos de Compromisso e, também, os ANPCs.

Por sua vez, o ANPC, tal como outros institutos de leniência, possui um diferencial frente aos demais acordos substitutivos, que é o de conferir um potencial maior de redução de custos para as atividades persecutória e sancionadora do Estado. Um tal acordo, quando celebrado em paralelo a uma leniência ou colaboração premiada, confere segurança jurídica à pessoa física que dele participa, incentivando o relato de ilícitos à autoridade estatal e, em paralelo, expondo outros infratores, exercendo influência relevante no comportamento dos coinfratores e tendo o potencial de induzir cada um deles a revelar, antes dos demais, a infração em troca de benefícios (ROSE-ACKERMAN; PALIFKA, 2016).

\footnotetext{
${ }^{6}$ Nas palavras de Guilherme Setoguti J. Pereira, enforcement corresponde ao "conjunto de atividades de investigação de possíveis violações da lei e de tomada de ações civis ou administrativas para inibir ou punir os responsáveis por essa violação, como a atividade de supervisionar e aplicar regras ou até mesmo como apenas medidas de aplicação de penalidades." (PEREIRA, 2018, p. 34)

7 "It is not sensible for regulators to aim for perfect compliance or the complete elimination of a risk. This is because enforcement costs tend to escalate as targeted levels of compliance are raised, and a point will arrive where the costs of further enforcement are not justified by the gains. Breyer refers to this as the problem of the last 10 per cent and quotes Sheldon Meyers: 'it frequently is relatively cheap to reduce risks from 0 to 90 per cent, more expensive to go from 90 per cent to 99 per cent and more expensive to go from 99 per cent to 99.9 per cent". (BALDWIN; CAVE; LODGE, 2013, p. 247).
} 
Cabe, neste ponto, a ressalva de que a eficácia e o sucesso desse instrumento de consensualidade dependerão da credibilidade das instituições que cuidarão do cumprimento e do controle do acordo, tanto para conferir segurança ao agente público que escolher esse método de resolução alternativa à mera aplicação da sanção, quanto para dar proteção ao indivíduo infrator e permitir o efetivo cumprimento do acordo. Por isso, a reputação, a lisura e a independência das instituições responsáveis pela persecução e negociação do acordo e pela sua homologação são elementos fundamentais para permitir a aplicação eficaz desse instituto ${ }^{8}$. Por óbvio, o nível de informação franqueada à coletividade também legitima o uso desses instrumentos consensuais, eis que é o povo quem, em última análise, exerce o controle derradeiro, o que se dá por meio do próprio processo democrático e da pressão que a opinião pública exerce sobre os Poderes da República.

O panorama geral ora apresentado coloca a solução negociada como importante instrumento de controle consensual à disposição dos agentes públicos. No item seguinte, o enfoque será a evolução normativa de acordos em matéria de improbidade administrativa. Investiga-se, no caso, como vem sendo desenvolvida a consensualidade no âmbito do Ministério Público Federal ${ }^{9}$.

\section{A EVOLUÇÃO NORMATIVA DE ACORDOS EM MATÉRIA DE IMPROBIDADE ADMINISTRATIVA}

Em sua redação original, a Lei nº 8.429/92 expressamente vedava a possibilidade de acordos relacionados às ações de improbidade administrativa. A situação foi alterada com a edição da MP nº 703/2015, pela então Presidente Dilma Rousseff, cuja vigência foi temporária, uma vez que perdeu sua eficácia em virtude de ausência de apreciação pelo Congresso Nacional.

\footnotetext{
${ }^{8}$ Outro fator relevante refere-se ao ambiente jurídico em que o administrador público exerce suas funções e as ameaças que podem advir do controle excessivo sobre seus atos. No Brasil, as alterações introduzidas na Lei de Introdução às Normas de Direito Brasileiro (LINDB - Lei 13.655/2018) propiciaram esse ambiente de maior segurança jurídica, permitindo ao gestor público a tomada de decisões pautadas na eficiência, desde que em respeito à precaução e ao interesse público correspondente.

${ }^{9}$ Nesse sentido, destaca-se: "In order for police officials who may abuse their power, one must set up a new cadre of monitors, such as Inspectors General, prosecutors, or judges, or all of these, who may proceed to commit abuses in their turn. The resulting question, 'Who guards the guardians' has a neat answer in principle: The guardians must be arranged in a circle, to enable mutual monitoring. But the necessary institutional arrangements produce costs of their own because the circle of mutual monitoring inevitably operates with a certain degree of friction, disagreement, conflict, and delay" (VERMEULE, 2019, p. 21).
} 
Referida norma pretendeu alterar o regramento do acordo de leniência estabelecido na Lei $n^{\circ}$ 12.846/2013 (Lei Anticorrupção) e, concomitantemente, previu a revogação da vedação de acordos para as ações de improbidade administrativa.

A análise da citada alteração legislativa permite apontar que a permissão legal para a realização de acordos em ações de improbidade foi pensada conjuntamente com o regramento de acordo de leniência. Infere-se, portanto, que a resolução consensual na seara da improbidade seria uma ferramenta para incentivar empresas privadas envolvidas em corrupção a firmarem acordos de leniência. Ou seja, entre os benefícios advindos da leniência, se incluiria a isenção de responsabilidade decorrente de um processo judicial por improbidade administrativa, permitindose a resolução consensual nessa senda.

A justificativa para tanto seria ampliar o incentivo para que a pessoa jurídica apresentasse provas de corrupção em acordo de leniência. Caso a extensão de efeitos na esfera da improbidade administrativa para a pessoa física não fosse possível, a situação poderia ser vista como geradora de insegurança jurídica. Isso porque, no âmbito da pessoa jurídica, teria sido firmado um acordo de leniência, negociando-se a diminuição de sanções financeiras em virtude da prática de condutas corruptas mediante o fornecimento de elementos probatórios sobre o esquema corrupto, enquanto no âmbito dos agentes dessa empresa - as pessoas físicas que ultimaram os atos corruptos - ainda penderia a possibilidade de responsabilização pessoal por ato de improbidade administrativa.

Por que um empresário iria entregar provas de corrupção de sua empresa, beneficiandose de redução das multas aplicáveis, mas, ao mesmo tempo, provendo elementos que o incriminassem pessoalmente no âmbito da improbidade administrativa? O raciocínio também pode ser aplicado para o acordo de colaboração premiada: só há incentivo para que o agente apresente provas incriminadoras se tais elementos não forem utilizados contra ele no âmbito da improbidade.

Porém, a MP no 703/2015 perdeu sua eficácia em 29 de maio de 2016, em meio ao processo de impeachment de Dilma Rousseff. Em decorrência, restou reestabelecida a redação original da Lei $\mathrm{n}^{\circ}$ 8.429/92, que não autorizava a celebração de acordos em ações de improbidade administrativa, criando um vácuo legislativo que, pelos motivos acima mencionados, trazia 
insegurança às pessoas físicas e jurídicas que negociavam e firmavam acordos de leniência e de colaboração premiada.

Após mais um ano sem qualquer sinalização concreta do Congresso Nacional para resolver esse vácuo, o Conselho Nacional do Ministério Público (CNMP) editou, em 26 de julho de 2017, a Resolução CNMP n 179. Por meio de tal normativo, o CNMP classifica a "ação de improbidade administrativa" como espécie do gênero "ação civil pública" com a finalidade de permitir a celebração de acordos em seu âmbito. Para tanto, toma emprestado, do microssistema da ação civil pública, o seu instrumento de consensualidade, qual seja, o "compromisso de ajustamento de conduta" (TAC), previsto no $\S 6^{\circ}$, do art. $5^{\circ}$, da Lei no 7.347/1985 (LACP).

A situação, no entanto, parecia contraditória. De um lado, com base na LACP e na Resolução CNMP no 179/2017, vislumbrava-se a possibilidade de TAC como ferramenta extrajudicial para a resolução de casos de improbidade administrativa. Por outro lado, estava em vigor a vedação, expressa na Lei $n^{\circ}$ 8.429/92, impedindo acordos em ações de improbidade administrativa.

Note-se que a celeuma se circunscrevia à interpretação da Lei $n^{\circ}$ 8.429/92, pois a vedação em questão se referia ao momento processual - ou seja, não seria mais possível a solução por acordo após iniciada a ação de improbidade? - ou representava um completo impedimento para a consensualidade em matéria de improbidade administrativa, independentemente do momento processual - ou seja, restariam proibidos acordos extrajudiciais e judiciais?

Havia o risco de que essa aparente contradição colocasse em dúvida a própria validade dos acordos extrajudiciais, enfraquecendo sua utilização. Imagine-se a insegurança de um agente ímprobo ao analisar suas alternativas: seria vantajoso firmar um acordo extrajudicial? Mas e se a efetividade desse acordo fosse posteriormente questionada, com base na interpretação de que a Lei $\mathrm{n}^{\text {o }}$ 8.429/92 veda a consensualidade em matéria de improbidade administrativa? Caso prevalecesse esse último entendimento, um agente ímprobo teria que responder por uma ação de improbidade administrativa apesar de já ter formalizado um acordo extrajudicial sobre o caso.

Diante desse cenário, foi editada a Lei no 13.964/2019, que alterou a redação da Lei $n^{\circ}$ 8.429/92, e passou a admitir a celebração de ANPC nas ações de improbidade. A inovação tem o 
potencial de gerar maior segurança jurídica para os acordos firmados em matéria de improbidade administrativa. A partir da vigência dessa lei, cessa qualquer dúvida acerca da admissão da consensualidade nessa seara.

Contudo, o problema agora é outro: se refere aos requisitos a serem observados para a formalização desses acordos. Em que pese a Lei no 13.964/2019, em sua redação original aprovada no Congresso Nacional, ter pretendido delimitar tais requisitos, o dispositivo legal que assim o fazia (art. 17-A da Lei $n^{\circ}$ 8.429/92) foi vetado quando de sua sanção pelo Presidente da República Jair Bolsonaro.

O dispositivo vetado tratava das seguintes questões principais: (i) estabelecia os parâmetros e trâmites que deveriam ser observados pelo membro do Ministério Público para que o acordo fosse possível; (ii) estipulava que o acordo também poderia ser celebrado no curso da ação judicial de improbidade administrativa.

$\mathrm{O}$ veto ao primeiro ponto (parâmetros a serem observados pelo Ministério Público) fundou-se na alegação de que o dispositivo legal, ao tratar apenas de acordos no âmbito no Ministério Público, poderia ser interpretado como uma exclusão da possibilidade de acordo por outros agentes legitimados para propor a ação de improbidade.

O veto ao segundo ponto (acordo no curso da ação judicial de improbidade) pautou-se na suposta contrariedade da norma ao "interesse público por ir de encontro à garantia da efetividade da transação e do alcance de melhores resultados, comprometendo a própria eficiência da norma jurídica que assegura a sua realização" (BRASIL, 2019d). Por sua vez, a alegada perda de eficiência estaria pautada na assunção de que "o agente infrator estaria sendo incentivado a continuar no trâmite da ação judicial, visto que disporia, por lei, de um instrumento futuro com possibilidade de transação" (BRASIL, 2019d).

A interpretação da regra jurídica deve ser conjugada com a redação do parágrafo 10-A, do artigo 17, da Lei $n^{\text {o }}$ 8.429/92, dispositivo também inserido pela Lei $\mathrm{n}^{\mathrm{o}}$ 13.964/2019, que estipula "havendo a possibilidade de solução consensual, poderão as partes requerer ao juiz a interrupção do prazo para a contestação, por prazo não superior a 90 (noventa) dias" (BRASIL, 1992; 2019c). Sua leitura permite concluir que a lei autoriza o acordo após o ajuizamento da 
ação de improbidade, mas restringe o momento: desde que antes da apresentação da contestação ${ }^{10}$.

Identifica-se quatro caminhos processuais para um acordo judicial: (i) no bojo de uma ação de improbidade administrativa, desde que antes da contestação, com fundamento nos $\S \S 1^{\circ}$ e 10-A, do artigo 17, da Lei nº 8.429/92; (ii) no bojo de uma ação de improbidade administrativa, mesmo após a sentença, admitindo-se o acordo em segunda instância, com fundamento no artigo 487, III, CPC e nos artigos 27 a 47, da Orientação n ${ }^{\circ} 10$, da $5^{\text {a }}$ CCR/MPF ${ }^{11}$; (iii) por meio de um procedimento de jurisdição voluntária de homologação de autocomposição extrajudicial, com fundamento no artigo 725, VIII, do Código de Processo Civil; (iv) por meio de um acordo de colaboração premiada, homologado na esfera criminal, mas que pode conter cláusula relacionada à repercussão cível dos atos investigados, exigindo-se nesse caso, como medida adicional, a homologação da $5^{\mathrm{a}} \mathrm{CCR} / \mathrm{MPF}$.

Além dessas opções, é possível ainda um acordo extrajudicial: ( $i$ ) formalizado por meio de TAC, com base na LACP e na Resolução CNMP n 179/2017, hipótese em que é dispensada a homologação do acordo pela $5^{\mathrm{a}} \mathrm{CCR} / \mathrm{MPF}$, conforme expressa previsão do artigo 65 , da Orientação $\mathrm{n}^{\mathrm{o}} 10$, da $5^{\mathrm{a}} \mathrm{CCR} / \mathrm{MPF}$; (ii) formalizado por meio de ANPC extrajudicial, exigindo-se a homologação do acordo pela $5^{\mathrm{a}} \mathrm{CCR} / \mathrm{MPF}$, nos termos do artigo 49 , da Orientação $n^{\circ} 10$, da $5^{\mathrm{a}}$ CCR/MPF; (iii) adesão pela pessoa física ao acordo de leniência, também sendo exigida a homologação do acordo pela $5^{\mathrm{a}} \mathrm{CCR} / \mathrm{MPF}^{12}$. São essas as soluções consensuais em matéria de improbidade administrativa.

\footnotetext{
${ }^{10}$ Importante esclarecer que a ação de improbidade administrativa possui um procedimento próprio, previsto nos $\S \S$ $7^{\circ}, 8^{\circ}$ e $9^{\circ}$, do artigo 17 , da Lei no $8.429 / 92$. Após o ajuizamento, o requerido é notificado para oferecer manifestação por escrito; analisando-se esses elementos iniciais, cabe ao juiz decidir: (i) se rejeitará a ação, caso convencido da inexistência do ato de improbidade, da improcedência da ação ou da inadequação da via eleita; (ii) se receberá a petição inicial, determinando a citação do réu para contestar.

${ }^{11}$ Aponte-se ressalva quanto à aplicação de dispositivo do Código de Processo Civil nesse caso. Isso porque, dentro do microssistema de tutela coletiva, no qual se insere a ação civil pública de improbidade administrativa, a aplicação do CPC é subsidiária e desde que não contrarie o regramento próprio (conforme expressamente consignado no artigo 19, da Lei $\mathrm{n}^{\circ}$ 7.347/85). No caso, o dispositivo da Lei $\mathrm{n}^{\circ} 13.964 / 2019$ que admitia o acordo a qualquer tempo foi expressamente vetado e, por conseguinte, entende-se pela inadequação da interpretação institucional de admitir o acordo mesmo após a sentença.

${ }^{12}$ Conforme Orientação $5^{\text {a }}$ CCR no $07 / 2017$ : “14. Assinado o acordo, o procedimento administrativo no qual estiver juntado deverá ser encaminhado à $5^{\text {a }} \mathrm{CCR}$, para homologação, por meio do Sistema Único, garantindo-se o necessário sigilo; 14.1.- Os anexos somente deverão ser encaminhados caso a Câmara os solicite, por ocasião da apreciação do acordo; 14.2.- No momento do encaminhamento dos autos à $5^{\text {a }} \mathrm{CCR}$, deverão ser feitos, nos autos, os
} 
As alterações legislativas criaram a certeza sobre a possibilidade de resolução consensual da responsabilização decorrente de ato de improbidade administrativa. Porém, perpetuou-se a insegurança a respeito dos procedimentos e requisitos exigíveis, em virtude da ausência de parâmetros legais para tanto.

Diante dessa lacuna, adquire relevância a regulação infralegal sobre o tema. Verifica-se diversidade dos requisitos exigidos para o acordo, a depender do normativo examinado. A Resolução CNMP n ${ }^{\circ}$ 179/2017 condiciona o TAC em improbidade administrativa ao ressarcimento ao erário e à aplicação de alguma penalidade prevista em lei ${ }^{13}$.

Por outro lado, no âmbito da $5^{\mathrm{a}} \mathrm{CCR} / \mathrm{MPF}$, a matéria é tratada, de maneira geral, na Orientação $\mathrm{n}^{\circ} 10$, e de maneira específica, por regular apenas a adesão de pessoa física ao acordo de leniência, na Orientação $n^{\circ} 7^{14}$. Alguns aspectos do regramento geral merecem ser destacados, pois fornecem elementos acerca da estrutura organizada sobre a temática. São listadas como modalidades de acordos no campo da improbidade administrativa: (i) Termo de Ajustamento de Conduta; (ii) ANPC (extrajudicial ou judicial, neste último caso admitindo-se sua pactuação em primeiro grau e, inclusive, em segundo grau de jurisdição, após a prolação de sentença); e (iii) acordo de leniência (art. $4^{\circ}, c a p u t$ ). Cada espécie possui requisitos e procedimentos próprios, sendo que a decisão acerca de qual instrumento utilizar, no caso concreto, é inserida dentro da independência funcional do membro (art. $4^{\circ}, \S 3^{\circ}$ ). Aponte-se, ainda, que o acordo extrajudicial por meio de TAC não exige a homologação da $5^{\mathrm{a}} \mathrm{CCR} / \mathrm{MPF}$, enquanto o ANPC extrajudicial exige essa homologação (artigos 65 e 67). Portanto, se o membro quiser evitar a supervisão imediata, basta escolher o TAC como ferramenta para o acordo. Além disso, os acordos formalizados por TAC não vão compor o banco de dados, a ser criado, com as informações sobre ANPC (art. 17, $\left.\S 4^{\circ}\right)$.

esclarecimentos que se entender necessários sobre os termos do acordo, inclusive sobre a forma de cálculo dos valores e multas acordadas." (MINISTÉRIO PÚBLICO, 2017).

${ }^{13} \mathrm{Cf}$. art. $1^{\circ}$, caput e $\S 2^{\circ}$ da resolução.

${ }^{14}$ A matéria é tratada em conjunto com o acordo de leniência previsto na Lei no 12.846/2013 (Lei Anticorrupção), assinalando-se que, às tratativas da pessoa jurídica, caberia a adesão por parte da pessoa física ligada àquela, para o que se exige a homologação do acordo pela $5^{\text {a }} \mathrm{CCR}$. Dentre as obrigações assinaladas pela $5^{\mathrm{a}} \mathrm{CCR}$ às pessoas físicas que optarem por aderir ao acordo de leniência, destacam-se o reconhecimento de sua participação no ilícito, a cessação de sua participação em tais atos e a obrigação de ressarcir os danos causados pelos ilícitos delatados dos quais tenha sido responsável. Aponte-se que a diretriz do órgão do Ministério Público Federal é no sentido de que o acordo não está condicionado, por lei, ao ressarcimento integral dos danos, denotando-se, por conseguinte, que o montante indenizatório seja objeto de negociação.

\section{Revista de Política Judiciária, Gestão e Administração da Justiça | e-ISSN: 2525-9822 |}


Relevante, ainda, uma breve abordagem sobre o processo legislativo que originou a Lei $n^{\circ} 13.964 / 2019$. Inicialmente, o Projeto de Lei n ${ }^{\circ} 10.372 / 2018$ pretendeu introduzir modificações na legislação penal e processual penal para aperfeiçoar o sistema de justiça, incluindo a hipótese de acordo de não persecução penal (ANPP), sendo que não havia qualquer dispositivo para alterar a Lei no 8.429/92. Posteriormente, o Projeto de Lei no 882/2019 também pretendeu regular a matéria, mas continha disposição para alterar o $\$ 1^{\circ}$, do artigo 17 , da Lei $n^{\circ} 8.429 / 92$, incluindose a possibilidade de acordo em matéria de improbidade administrativa, consensualidade que poderia ser formalizada por instrumentos diversos - acordo de colaboração premiada, leniência ou $\mathrm{TAC}^{15}$.

Em vista da duplicidade de projetos sobre a mesma matéria, o Presidente da Câmara dos Deputados decidiu, então, promover a tramitação conjunta das referidas proposições. Em virtude da conexão da matéria tratada em ambas, entendeu-se pela necessidade de comparação e, eventualmente, harmonização (BRASIL, 2019a). Assim, em 13 de março de 2019, o PL no 882/2019 foi apensado ao PL n 10.372/2018, para tramitação conjunta. Ademais, foi criado um Grupo de Trabalho para realizar a análise, em diálogo com o Conselho Nacional de Justiça. O respectivo relatório sugeriu que a possibilidade de acordo em matéria de improbidade administrativa fosse mantida, nos termos propostos ${ }^{16}$. Posteriormente, houve a votação em plenário de um substitutivo, resultado da "compatibilização" das citadas proposições (BRASIL, 2018). Nessa ocasião, a proposta de redação do $\S 1^{\circ}$, do artigo 17, da Lei $n^{\circ} 8.429 / 92$ foi alterada, fixando o ANPC como o instrumento previsto para a resolução consensual da improbidade administrativa. Foi essa, ao final, a versão do projeto de lei aprovada.

Não obstante, a normatização infralegal manteve a diversidade de instrumentos consensuais em matéria de improbidade administrativa: TAC, ANPC, acordo de leniência. A confusão tem o potencial de dificultar o controle social, ou seja, o escrutínio realizado pela coletividade, dado que o TAC pode ter como objeto diversas matérias de tutela coletiva, e não

\footnotetext{
${ }^{15}$ Previa-se a seguinte redação: "§ $1^{\circ} \mathrm{A}$ transação, o acordo ou a conciliação nas ações de que trata este artigo poderão ser celebradas por meio de acordo de colaboração ou de leniência, de termo de ajustamento de conduta ou de termo de cessação de conduta, com aplicação, no que couber, das regras previstas na Lei $\mathrm{n}^{\circ} 12.850$, de 2 de agosto de 2013, e na Lei $\mathrm{n}^{\circ} 12.846$, de $1^{\circ}$ de agosto de 2013." (BRASIL, 2019b)

16 "Diante disso, mostra-se correta a alteração sugerida pela proposição em análise, razão pela qual incorporo tal sugestão em minha proposta de harmonização" (BRASIL, 2019a, p. 153).
} 
apenas improbidade administrativa. O seu emprego, portanto, dificulta o conhecimento, pela sociedade, dos agentes ímprobos que tenham sido beneficiados por um acordo.

Feitos os esclarecimentos necessários para que se compreenda o quadro normativo, passa-se a averiguar se a Lei $n^{\circ} 13.964 / 2019$, ao introduzir a figura do ANPC no âmbito da improbidade administrativa, teria provocado o aumento da resolução consensual em tais casos.

\section{METODOLOGIA E ANÁLISE DE RESULTADOS}

A evolução normativa traçada indica, no atual cenário, a possibilidade jurídica de acordo extrajudicial em matéria de improbidade administrativa. Esta pesquisa pretende verificar se o volume de acordos extrajudiciais, no âmbito do Ministério Público Federal, sofreu algum impacto com a edição da Lei $n^{\circ} 13.964 / 2019^{17}$. A análise tem o potencial de desvendar o real sistema da consensualidade em matéria de improbidade administrativa: seria uma novidade inaugurada com a alteração legislativa? Ou a modificação legal veio apenas para ratificar uma prática já consolidada?

Considerando-se a função revisora da $5^{\mathrm{a}} \mathrm{CCR} / \mathrm{MPF}$, buscou-se examinar o histórico do quantitativo de acordos homologados pelo órgão, a partir de agosto de 2017, data de publicação da Resolução CNMP n 179/2017, para avaliar se houve alguma alteração com a edição da Lei $n^{\circ}$ 13.964/2019. Dessa forma, procedeu-se à consulta das atas de reuniões da $5^{\mathrm{a}} \mathrm{CCR} / \mathrm{MPF}^{18}$. A metodologia empregada se justifica na medida em que o procedimento extrajudicial, no âmbito do MPF, é regulado pela Resolução CSMPF no 87/2010, que determina, em caso de TAC, sua

\footnotetext{
${ }^{17}$ Importante registrar que se trata de análise parcial, na medida em que não considera, em seu universo, eventuais acordos judiciais. No entanto, entende-se que há grande benefício para a solução extrajudicial e, por tal razão, imagina-se que a maior parte dos acordos seja verificada nessa esfera. Em verdade, a normatização do MPF indica que deve ser priorizada a resolução extrajudicial dos conflitos, conforme parágrafo único, do artigo $6^{\circ}$, da Orientação $5^{a} \operatorname{CCR~n}{ }^{\circ} 10 / 2020$. Ademais, os sistemas da justiça federal são diferentes em cada região e, por não existir uma unificação, constatou-se um óbice à pesquisa de caráter nacional envolvendo acordos judiciais. Assim, optou-se pela restrição aos acordos extrajudiciais.

${ }^{18}$ Referidos documentos não revelam o inteiro teor dos acordos, apenas indicando a decisão colegiada acerca da homologação. Dessa forma, não é possível fazer uma análise aprofundada sobre os quantitativos apresentados. Por exemplo, é verificada uma grande quantidade de acordos em maio de 2019; porém, os dados disponíveis não permitem apresentar uma explicação para o fato. Disponíveis em <http://www.mpf.mp.br/atuacaotematica/ccr5/revisao/atas-de-reunioes/atas-de-reunioes>. Acesso em 08 nov. 2020. Registre-se que os arquivos disponibilizados não possuem sequenciamento numérico, portanto, é possível que não tenham sido publicadas as atas de todas as reuniões do colegiado.
}

\section{Revista de Política Judiciária, Gestão e Administração da Justiça | e-ISSN: 2525-9822 |}


comunicação à respectiva Câmara de Coordenação e Revisão (art. 21, §5²) ${ }^{19}$. Assim, foram acessados todos os arquivos públicos das sessões realizadas pelo referido órgão, e o resultado é apresentado a seguir:

${ }^{19}$ Adicionalmente, cumpre esclarecer que a negociação de um TAC ocorrerá, necessariamente, no bojo de um inquérito civil público, conforme expressamente previsto no parágrafo único, do artigo $1^{\circ}$, da Resolução CSMPF ${ }^{\circ}$ 87/2006. E a finalização regular desse tipo de procedimento administrativo exige a homologação do respectivo órgão revisor, nos termos do $\S 2^{\circ}$, do artigo 17, da Resolução CSMPF $n^{\circ} 87 / 2006$. Em virtude dessa sistemática, entende-se que a regra é a homologação do acordo pela $5^{\text {a }} \mathrm{CCR} / \mathrm{MPF}$, ainda que indiretamente, na oportunidade de homologação do arquivamento. 
Daniela Thomes Coelho \& João Felipe Viegas Figueira de Mello

Tabela 1

\begin{tabular}{|c|c|c|c|c|c|}
\hline ANO & MÊS & $\begin{array}{c}\text { Quantitativo } \\
\text { de acordos de } \\
\text { leniência } \\
\text { submetidos à } \\
\text { apreciação da } \\
5^{\text {a }} \text { CCR/MPF } \\
\text { (beneficiado: } \\
\text { PJ) }\end{array}$ & $\begin{array}{c}\text { Quantitativo de } \\
\text { adesão de } \\
\text { preposto ao } \\
\text { acordo de } \\
\text { leniência ou } \\
\text { homologação de } \\
\text { aspectos cíveis } \\
\text { de acordo de } \\
\text { colaboração } \\
\text { premiada } \\
\text { (beneficiado: } \\
\text { PF) }\end{array}$ & $\begin{array}{c}\text { Quantitativo } \\
\text { de acordos } \\
\text { homologados } \\
\text { pela } 5^{\text {a }} \\
\text { CCR/MPF }\end{array}$ & $\begin{array}{c}\text { Quantitativo } \\
\text { de acordos } \\
\text { sigilosos }\end{array}$ \\
\hline 2017 & agosto & 0 & 0 & 0 & 0 \\
\hline 2017 & setembro & 1 & 0 & 1 & 1 \\
\hline 2017 & outubro & 1 & 0 & 1 & 1 \\
\hline 2017 & novembro & 0 & 0 & 0 & 0 \\
\hline 2017 & dezembro & 0 & 0 & 0 & 0 \\
\hline 2018 & fevereiro & 1 & 2 & 3 & 3 \\
\hline 2018 & março & 0 & 0 & 0 & 0 \\
\hline 2018 & abril & 1 & 1 & 2 & 2 \\
\hline 2018 & maio & 2 & 1 & 3 & 3 \\
\hline 2018 & junho & 1 & 3 & 4 & 4 \\
\hline 2018 & agosto & 2 & 0 & 2 & 2 \\
\hline 2018 & setembro & 2 & 2 & 4 & 4 \\
\hline 2018 & outubro & 0 & 0 & 0 & 0 \\
\hline 2018 & novembro & 3 & 0 & 3 & 3 \\
\hline 2018 & dezembro & 3 & 0 & 3 & 3 \\
\hline 2019 & fevereiro & 1 & 3 & 4 & 4 \\
\hline 2019 & março & 1 & 4 & 5 & 5 \\
\hline 2019 & abril & 3 & 3 & 5 & 6 \\
\hline 2019 & maio & 0 & 0 & 0 & 0 \\
\hline 2019 & junho & 2 & 0 & 2 & 2 \\
\hline 2019 & julho & 1 & 0 & 1 & 1 \\
\hline 2019 & agosto & 1 & 3 & 3 & 4 \\
\hline 2019 & setembro & 5 & 0 & 4 & 5 \\
\hline 2019 & outubro & 2 & 4 & 3 & 6 \\
\hline 2019 & novembro & 1 & 0 & 1 & 1 \\
\hline 2019 & dezembro & 0 & 2 & 2 & 2 \\
\hline 2020 & janeiro & 0 & 1 & 1 & 1 \\
\hline 2020 & fevereiro & 1 & 1 & 2 & 2 \\
\hline 2020 & março & 1 & 1 & 2 & 2 \\
\hline 2020 & abril & 1 & 3 & 4 & 3 \\
\hline 2020 & maio & 1 & 12 & 13 & 12 \\
\hline 2020 & junho & 2 & 0 & 2 & 2 \\
\hline 2020 & agosto & 1 & 1 & 2 & 2 \\
\hline 2020 & setembro & 2 & 0 & 2 & 2 \\
\hline
\end{tabular}

Fonte: produção própria

$\mathrm{Na}$ documentação da $5^{\mathrm{a}} \mathrm{CCR} / \mathrm{MPF}$ não foi identificada a utilização da expressão “acordo de não persecução cível”. As duas colunas apontam os resultados para dois termos 
identificados: na coluna "quantitativo de acordos de leniência submetidos à apreciação da $5^{\text {a }}$ CCR/MPF” foram incluídas as situações em que o beneficiário é uma pessoa jurídica; na coluna “quantitativo de adesão de preposto ao acordo de leniência ou homologação de aspectos cíveis de acordo de colaboração premiada" são apontados acordos cujos beneficiários são pessoas físicas.

Considerando-se que a sistemática da Lei no 8.429/92 é aplicável aos agentes ímprobos, enquanto pessoas físicas, conclui-se que é a segunda coluna que contém os dados de interesse para esta pesquisa, que são condensados na tabela seguinte:

\begin{tabular}{cc}
\hline Ano & Total de acordos \\
\hline 2017 (parcial) & 0 \\
\hline 2018 & 9 \\
\hline 2019 & 19 \\
\hline 2020 (parcial) & 19 \\
\hline
\end{tabular}

\section{Tabela 2}

\section{Fonte: produção própria}

A Lei n ${ }^{\circ} 13.964 / 2019$, que introduziu o ANPC na Lei $n^{\circ} 8.429 / 92$, entrou em vigor em 23/01/2020. A comparação dos quantitativos de acordos homologados pela $5^{\text {a }}$ CCR/MPF antes e depois dessa inovação legislativa permite inferir que a realidade prática não foi significativamente impactada com a introdução desse instrumento. Os achados, portanto, indicam que o nível de acordos extrajudiciais em matéria de improbidade administrativa manteve-se praticamente constante, mesmo após a alteração legislativa. Assim, é possível concluir que se trata de mera ratificação de uma interpretação institucional prévia que já admitia acordos em matéria de improbidade administrativa, apesar da expressa vedação então inserida na Lei $n^{\circ} 8.429 / 92$. 
É relevante, ainda, destacar que a Lei $n^{\text {o }} 13.964 / 2019$ possui expressamente fundamentação utilitarista: pretendeu introduzir medidas de justiça consensual, inclusive no âmbito penal, com o objetivo de diminuir o congestionamento de processos. Porém, sob a ótica da improbidade administrativa, o quantitativo de acordos firmados extrajudicialmente, de aproximadamente 20 a cada ano, é ínfimo em vista do volume processual da Justiça Federal. Ou seja, impedir o início de 20 processos, por meio de acordo extrajudicial, não pode ser vista como medida capaz de impactar o gerenciamento da carga processual. Ilustrativamente, relatório do CNJ indica, em relação aos casos novos na Justiça Federal, não-criminais, em 2019, o total de 4.083.424 (CONSELHO NACIONAL DE JUSTIÇA, 2019).

Nesse contexto, verifica-se que a principal utilidade de admissão da consensualidade, na esfera da improbidade administrativa, não está atrelada ao gerenciamento do congestionamento processual. Nos casos examinados, os acordos estavam relacionados a condutas criminais, posto que firmados conjuntamente com acordos de colaboração premiada ou leniência. Portanto, a negociação da responsabilização decorrente da improbidade administrativa pode ser vista como um acessório, integrante da complexa sistemática de enfrentamento à corrupção.

\section{CONSIDERAÇÕES FINAIS}

O estudo demonstrou que a admissão da consensualidade, em matéria de improbidade administrativa, foi construída por interpretação institucional do próprio Ministério Público Federal. Assim, a alteração introduzida pela Lei nº 13.964/2019 teve o efeito de gerar segurança jurídica para as negociações que já eram realizadas, mas não provocou impacto no sentido de aumentar o quantitativo de acordos extrajudiciais.

A descrição do regramento aplicável demonstra que o controle consensual de atos de improbidade administrativa pode ser realizado por diversos caminhos. Uma das consequências é a dificuldade de informação sistematizada sobre os agentes ímprobos. Isso porque quando o agente está respondendo por uma ação de improbidade administrativa, essa informação está disponível no respectivo sistema judicial. Entretanto, quando o agente ímprobo foi beneficiado por um acordo, apesar de ter admitido a prática ilícita, a divulgação pública de tais agentes não é realizada de maneira organizada. A dificuldade ocorre porque grande parte dos acordos de leniência e colaborações premiadas são sigilosos, para preservar a utilidade da investigação; 
além disso, os compromissos de ajustamento de condutas, por serem ferramentas extrajudiciais, não estão disponíveis prontamente ao público; e o posicionamento institucional do Ministério Público Federal pretende a divulgação exclusivamente dos acordos firmados por meio de ANPC, não incluindo o TAC.

No caso de solução consensual, há confissão de atos de improbidade sem que os agentes possam ser facilmente identificados pela população como tal. Quais agentes admitiram a prática de ato de improbidade administrativa? Contudo, essa informação é sigilosa. Por outro lado, os agentes que estão sendo processados por improbidade administrativa - restando-se ainda dúvida sobre sua culpabilidade, haja vista a inexistência ainda de condenação -, são facilmente apontados, já que os dados resultam de consulta às ações de improbidade em curso.

Haveria, portanto, uma incongruência: agentes ímprobos confessos se perdem no sistema de informação, enquanto supostos agentes ímprobos que ainda respondem à processo judicial são facilmente identificados.

A pergunta que se coloca, portanto, é: não seria interesse da coletividade a divulgação organizada de agentes ímprobos confessos? Trata-se de informação sensível e relevante, por exemplo para a avaliação de candidato político em potencial ou ocupante de função pública.

Assim, sugere-se que o CNMP organize, em esfera nacional, a gestão de sistema de informação sobre os agentes ímprobos que formalizaram qualquer tipo de acordo em matéria de improbidade administrativa, como forma de se garantir a transparência aos cidadãos.

Também merece controle social a conduta dos membros do Ministério Público. A consensualidade confere espaço para certa margem de liberalidade por parte dos pactuantes. E, em uma democracia, o exercício de um poder deve se sujeitar ao escrutínio da sociedade, como forma de controle. Trata-se da atuação de um agente público, que deve ser alinhada com os interesses da comunidade. Porém, esse alinhamento é difícil no Brasil em virtude da estrutura da carreira do Ministério Público.

Comparativamente, veja-se a organização nos Estados Unidos: há ampla liberdade para os promotores negociarem acordos através de plea bairgain; mas os promotores ocupam cargos 
eletivos; logo, há controle político e democrático de sua atuação, já que, em caso de abusos, a carreira do agente estaria prejudicada ${ }^{20}$.

Diferentemente, no Brasil os membros do Ministério Público ocupam cargos vitalícios; logo, não existe qualquer tipo de controle social sobre suas atuações. É possível a perda do cargo como consequência de atividade ilegal judicialmente reconhecida; entretanto, não existe uma estrutura que alinhe a conduta dos membros aos anseios da sociedade. Portanto, a margem de discricionariedade para negociações pode refletir convicções pessoais de cada membro, em vez de representar a vontade da comunidade.

Diante disso, entende-se que o mínimo aceitável seria que o conteúdo dos acordos fosse de fácil acesso ao público, para permitir algum tipo de controle social. Assim, seria possível identificar quais as condições estipuladas por cada membro do Ministério Público, gerando certa responsabilização social, sem prejuízo de outras soluções que possam ser aventadas para garantir o alinhamento do órgão ministerial.

\section{REFERÊNCIAS BIBLIOGRÁFICAS:}

ALSCHULER, Albert W. The Prosecutor's Role in Plea Bargaining. University of Chicago Law Review, v. 36, n. 1, p. 50-112, 1968.

BALDWIN, Robert; CAVE, Martin; LODGE, Martin. Understanding Regulation: Theory, Strategy, and Practice. Second Edition, Oxford University Press, 2013.

BECKER, Gary. Crime and Punishment: An Economic Approach. Journal of Political Economics, 1968.

BOBBIO, Norberto. Da Estrutura à Função: novos estudos de teoria do direito. Barueri, SP: Editora Manole, 2007.

BRASIL. Câmara dos Deputados. Ato do Presidente de 14 de março de 2019. Disponível em: <https://www.camara.leg.br/proposicoesWeb/prop_mostrarintegra?codteor $=1772332 \&$ filename $=$ Tramitacao-PL+10372/2018>. Acesso em 16 dez. 2020.

BRASIL. Câmara dos Deputados. Projeto de Lei no 10.372-A de 2018. Aperfeiçoa a legislação penal processual penal. Disponível em:

${ }^{20}$ Criticando o caráter político dos promotores norte-americanos ver: ALSCHULER, Albert W. The Prosecutor's Role in Plea Bargaining. University of Chicago Law Review, v. 36, n. 1, p. 50-112, 1968. 
<https://www.camara.leg.br/proposicoesWeb/prop_mostrarintegra?codteor=1844037\&filename= Tramitacao-PL+10372/2018>. Acesso em 3 abr. 2021.

BRASIL. Câmara dos Deputados. Projeto de Lei no 882 de 2019. Altera a legislação penal e processual penal Disponível em: <https://www.camara.leg.br/proposicoesWeb/prop_mostrarintegra?codteor=1719464>. Acesso em 3 abr. 2021.

BRASIL. Lei $\mathrm{n}^{\circ}$ 8.429, de 2 de junho de 1992. Lei de Improbidade Administrativa. Disponível em: http://www.planalto.gov.br/ccivil_03/LEIS/L8429.htm\#: :text=LEI\%20N\%C2\%BA\%208.429\% 2C\%20DE\% 202\%20DE\%20JUNHO\%20DE\%201992\&text=Disp\%C3\%B5e\%20sobre\%20as\% 20san\%C3\%A7\%C3\%B5es\%20aplic\%C3\%A1veis, fundacional\%20e\%20d\%C3\%A1\%20outras \%20provid\%C3\%AAncias.> . Acesso em 3 abr. 2021.

BRASIL. Lei no 13.964, de 24 de dezembro de 2019. Aperfeiçoa a legislação penal e processual penal. Disponível em: <http://www.planalto.gov.br/ccivil_03/_Ato20192022/2019/Lei/L13964.htm\#art6>. Acesso em 3 abr 2021.

BRASIL. Mensagem $\mathrm{n}^{\mathrm{o}}$ 726, de 24 de dezembro de 2019. Disponível em: <http://www.planalto.gov.br/ccivil_03/_ato2019-2022/2019/Msg/VEP/VEP-726.htm>. Acesso em 2 abr. 2021.

CONSELHO NACIONAL DE JUSTIÇA. Justiça em números. 2019. Disponível em: < https://www.cnj.jus.br/wp-

content/uploads/conteudo/arquivo/2019/08/justica_em_numeros20190919.pdf> . Acesso em 3 abr. 2021.

DE PALMA, Juliana Bonacorsi. Sanção e Acordo na Administração Pública. São Paulo: Malheiros, 2015.

FREEMAN, Jody. The private role in public governance. New York University Law Review 75/571, 2000. Disponível em: <https://papers.ssrn.com/sol3/papers.cfm?abstract_id=231856>. Acesso em 2 de abril de 2020.

GARCIA, Emerson. A consensualidade no direito sancionador brasileiro: potencial incidência no âmbito da Lei no 8.429/1992. Revista síntese. São Paulo, v. 12, n. 141, p. 542-595, 2017.

GARCIA, Emerson; ALVES, Rogério Pacheco. Improbidade Administrativa. 9. ed. São Paulo: Saraiva, 2017.

LOBEL, Orly. The renew deal: the fall of regulation and the rise of governance in contemporary legal thought. Minnesota Law Review, 663, 2004, p. 341-470 Disponível em: < https://core.ac.uk/download/pdf/217211732.pdf>. Acesso em 2 de abril de 2021. 
MACHADO, Antonio Rodrigo. Sanções e Penas: a independência entre as instâncias administrativa e judicial. Rio de Janeiro: Lumen Juris, 2020.

MEDAUAR, Odete. O Direito Administrativo em Evolução. $3^{\mathrm{a}}$ Edição. Brasília, DF: Gazeta Jurídica, 2017.

MINISTÉRIO PÚBLICO. Orientação $5^{\mathrm{a}}$ CCR $\mathrm{n}^{\mathrm{o}} 07$ de 2017. Disponível em <http://www.mpf.mp.br/pgr/documentos/ORIENTAO7_2017.pdf.>. Acesso em 07 nov. 2020.

OSÓRIO, Fabio Medina. Direito Administrativo Sancionador. $7^{\text {a }}$ Edição. São Paulo: Thomsom Reuters Brasil, 2020.

PEREIRA, Setoguti J. Enforcement e tutela indenizatória no Direito Societário e no Mercado de Capitais. São Paulo: Ed. Quartier Latin, 2018.

ROSE-ACKERMAN, Susan; PALIFKA, Bonnie J. Corruption and Government: Causes, Consequences, and Reform. Second Edition, Cambridge University Press, 2016.

VERMEULE, Adrian. Optimal abuse of power. Administrative Law Review, Rio de Janeiro, v. 278, n. 3, p. 15-43, 2019.

VORONOFF, Alice. Direito Administrativo Sancionador no Brasil: Justificação, interpretação e aplicação, 2a reimpressão, Belo Horizonte: Fórum, 2019. 